\title{
Music is Beneficial for Awake Craniotomy Patients: A Qualitative Study
}

\author{
Radhika Jadavji-Mithani, Lashmi Venkatraghavan, Mark Bernstein
}

\begin{abstract}
Objectives: Patients undergoing awake craniotomy may experience high levels of stress. Minimizing anxiety benefits patients and surgeons. Music has many therapeutic effects in altering human mood and emotion. Tonality of music as conveyed by composition in major or minor keys can have an impact on patients' emotions and thoughts. Assessing the effects of listening to major and minor key musical pieces on patients undergoing awake craniotiomy could help in the design of interventions to alleviate anxiety, stress and tension. Methods: Twenty-nine patients who were undergoing awake craniotomy were recruited and randomly assigned into two groups: Group 1 subjects listened to major key music and Group 2 listened to minor key compositions. Subjects completed a demographics questionnaire, a pre- and post-operative Beck Anxiety Inventory (BAI) and a semi-structured open-ended interview. Results were analyzed using modified thematic analysis through open and axial coding. Results: Overall, patients enjoyed the music regardless of the key distinctions and stated they benefitted from listening to the music. No adverse reactions to the music were found. Subjects remarked that the music made them feel more at ease and less anxious before, during and after their procedure. Patients preferred either major key or minor key music but not a combination of both. Those who preferred major key pieces said it was on the basis of tonality while the individuals who selected minor key pieces stated that tempo of the music was the primary factor. Conclusion: Overall, listening to music selections was beneficial for the patients. Future work should further investigate the effects of audio interventions in awake surgery through narrative means.
\end{abstract}

RÉSUMÉ: La musique est bénéfique chez les patients qui subissent une craniotomie en état vigile : une étude qualitative. Objectifs: Une craniotomie peut provoquer un stress important chez les patients et tant les patients que les chirurgiens bénéficient d'une réduction de l'anxiété. La musique a plusieurs effets thérapeutiques sur l'humeur et les émotions chez les humains. La tonalité de la musique d'œuvres en mode majeur et d'œuvres en mode mineur peut avoir un impact sur les émotions et les pensées des patients. Le but de l'étude était d'évaluer les effets sur les patients d'œuvres musicales en mode majeur et d'œuvres en mode mineur pendant la craniotomie en état vigile afin d'aider à élaborer des interventions destinées à soulager l'anxiété, le stress et la tension. Méthode: Nous avons recruté 29 patients qui subissaient une craniotomie en état vigile. Ils ont été randomisés en deux groupes : les patients du groupe 1 écoutaient de la musique en mode majeur et ceux du groupe 2 écoutaient de la musique en mode mineur. Les sujets ont complété un questionnaire démographique, l'inventaire d'anxiété de Beck avant et après la chirurgie et une entrevue semi-structurée à questions ouvertes. Les résultats ont été analysés au moyen d'une analyse thématique modifiée, par codage ouvert et codage axial. Résultats: En général, les patients ont écouté la musique avec plaisir, que les œuvres soient en mode majeur ou en mode mineur, et ils ont rapporté qu'ils en avaient tiré bénéfice. Aucune réaction négative à la musique n'a été rapportée. Les sujets ont indiqué que, grâce à la musique, ils se sentaient plus à l'aise et moins anxieux avant, pendant et après l'intervention. Les patients ont préféré soit les œuvres en mode majeur, soit les œuvres en mode mineur, mais pas une combinaison d'œuvres des deux modes. Ceux qui ont préféré les œuvres en mode majeur ont dit que c'était la tonalité qui leur avait plu alors que pour ceux qui avaient préféré le mode mineur c'était le rythme de la musique qui était le principal facteur motivant leur choix. Conclusion : Globalement, les patients ont bénéficié de l'écoute d'œuvres musicales. Des études plus poussées devraient explorer par la narration les effets de telles interventions lors de la chirurgie en état vigile.

Keywords: Awake craniotomy, major key, minor key, music therapy, qualitative research

doi:10.1017/cjn.2014.127

Can. J. Neurol. Sci. 2015; 42: 7-16

Approximately 50 million surgical procedures are performed annually in the United States. Reports indicate that the majority of these patients experience significant levels of anxiety, nervousness and fear regarding surgery especially in the pre-operative stages. ${ }^{35}$ Review of the literature reveals that these feelings are attributable to the fear of unfamiliar surroundings, fear of outcomes post-surgery, loss of control and fear of death. ${ }^{1}$ Over the years various forms of interventions, such as thorough patient education, contemplation, hypnosis, and medication, amongst others, have attempted to improve the patient experience and reduce stress induced by surgeries. ${ }^{38}$
Music has been long known to reduce stress, anxiety and tension, as well as relieve pain in both everyday and clinical settings. ${ }^{26}$ The therapeutic effects provided by music are recognized to be both

From the Division of Neurosurgery, University of Toronto (MB); Division of Neurosurgery and Department of Anesthesia (RJ-M, LV), Toronto Western Hospital, University Health Network, Toronto, Canada.

Received May 28, 2014. Final Revisions Submitted November 19, 2014. Correspondence to: Mark Bernstein, University of Toronto, Toronto Western Hospital, Division of Neurosurgery, 399 Bathurst Street, 4W451, Toronto, Ontario, Canada, M5T 2S8. Email:mark.bernstein@uhn.on.ca 
physiological and psychological in nature and have been demonstrated in a number of clinical studies that offered patients a music intervention at some point in their course of treatment. ${ }^{2,7,9,10,11,15,27}$ The use of music as a non-pharmacological medium may potentially improve the pre-operative, perioperative and post-operative (recovery) situations of surgical patients without interfering with planned treatment and prescribed medications. ${ }^{7}$ Music therapy has been used in the past to help alleviate pre-operative anxiety. ${ }^{38}$ In 1914, Evan O'Neill Kane became the first surgeon to play music to patients in the operating room through a phonograph. He believed the music had a " "calming effect' that helped patients escape the horrors of surgery". ${ }^{20}$ Other studies related to music and its ability to attenuate discomfort and enhance relaxation in patients, have been reported in medical specialties such as psychiatry, pediatrics, obstetrics, orthopedics, ophthalmology, and even cardiac surgery. ${ }^{12,14,16,28}$ Very few studies have examined the effect of music on brain surgery patients. Although it can be assumed that all surgical patients experience at the least some levels of stress and anxiety near the time of surgery, regardless of the type of surgery they will be undergoing, brain surgery is still considered one of the more complex procedures in medicine and may result in this group of surgical candidates experiencing higher levels of emotional distress than others. ${ }^{36}$ Furthermore, of this special subset of patients, many undergo an awake craniotomy. In this procedure patients are provided local anesthesia instead of the usual general anesthetics, resulting in patients that are awake, cognizant of the situation and able to respond to surgeons' requests during their procedures. ${ }^{36}$ Awake craniotomy allows neurosurgeons to perform brain mapping to facilitate safe, maximal resection of tumors and epileptogenic foci. ${ }^{34}$ Remaining awake during the length of the brain surgery, or even a portion of the surgery, increases patient anxiety levels. Patients may be alarmed and frightened when first informed about needing to undergo an awake cranial surgery. ${ }^{18}$ However a previous study by our group demonstrated low degrees of anxiety and high levels of satisfaction. ${ }^{22}$ Our present study aims to acquire a better understanding regarding music and its role in helping to ameliorate surgically related stress and optimize overall hospital experience for patients undergoing awake craniotomy.

There are many theories as to why and how music helps relieve surgically related anxiety and stress. One idea is that music enables the body to synchronize its own rhythms with the rhythms of surrounding vibrating bodies. ${ }^{25}$ Thus, in essence, an anxious patient with an initially racing heart beat and sweat gland response, when listening to slow music, will experience their heart rate and sweating response mimic the rhythm of the music and thus slow down. Another idea claims that the act of listening to music provided through headphones masks sounds and conversations created by the surgical staff thereby shielding awake patients from listening to things which may not comfort them. ${ }^{25}$ In addition, the music may give patients on the table something other than the procedure to concentrate on; in this sense the music would act as a distraction to the noise, conversations, feelings and smells the patient would be experiencing.

While musical intervention is important, it is crucial that the music be appropriately selected for the clinical scenario. Not all forms of music are stress and anxiety relieving. Different genres of music and also the instruments used to create musical pieces affect human mood, emotion and even physiological responses in varying ways. Heavy metal music is not known to induce relaxation and calmness while soft flute tunes have often been noted to stimulate deep relaxation states. ${ }^{24}$ Few studies have discussed the benefits of Medical Resonance Therapy Music (MRTMusic) and its underlying concept of "sympathetic resonance" to help individuals in the medical setting. ${ }^{23}$ Sympathetic resonance is a phenomenon in which a complex harmonic vibration is created when the natural vibration frequency of a string or vibratory body activates another vibration of a similar harmonic nature. This phenomenon can be demonstrated by the use of string instruments such as the violin, harp, harpsichord, guitar, and piano. ${ }^{33}$ When sound signals entering the left and right ears are altered, a 'frequency modulated pulse' arises which causes a neural response. This response has shown a slowing of brainwave activity which can be associated with stress reduction and relaxation among other notable characteristics of this 'brainwave entrainment' phenomenon.

Tonality and various themes of music can evoke different emotions in individuals. ${ }^{17,21,30}$ Similar to how background music of a wedding scene (typically composed in major keys) in a movie can evoke feelings of happiness in a viewer, music played in major keys may also elicit positive emotions in patients. Conversely, background music of a break-up scene (typically composed in minor keys) can evoke feelings of sadness and so, theoretically, music played in minor keys may induce negative emotions in patients. Besides our primary aim to better understand the overall effect of music on awake craniotomy patients, we also explored the impact of tonal structure (i.e. the influence of key change) in music on patients' mood states.

\section{MethodS}

\section{Subjects}

Patients were selected from the clinic of the senior author (MB) in the Neurosurgery Division at Toronto Western Hospital. The main inclusion criteria included: (1) the patient was scheduled for an awake craniotomy; and (2) agreement of the patient to provide written informed consent to participate in the study. Patients who were: (1) <18 years of age, (2) suffered from severe hearing impairment, or (3) not sufficiently cognitively intact, were excluded from the study.

\section{Sample Size}

Twenty-nine interviews were conducted on eligible and consented patients. This sample size was selected because it was deemed sufficient in attaining data saturation levels. Saturation is a notion in qualitative research that describes the situation in which, at some point, successive interviews will not yield any new concepts or ideas beyond ones that have already arisen. ${ }^{6}$ Patients were accrued by convenience sampling during two periods: May through August of 2012 and May through August of 2013.

\section{Study Design}

This study was conducted using a prospective qualitative research methodology. Patients who were scheduled to undergo awake craniotomy for brain tumor or epilepsy were interviewed using a semi-structured, open-ended questionnaire and completed a self-administered survey commenting on overall hospital experience and quality of life measures. Patients' perceptions of listening to music during the perioperative period were explored.

Patients who were scheduled for awake craniotomy were enrolled into the study through both verbal and written informed 
consent. General information regarding their overall hospital stay was given and subjects were informed that they would be fitted with a pair of noise-cancelling headphones which would play a pre-determined selection of instrumental music before, during, and after their surgical procedure should they consent to the study. Upon consent, subjects completed a demographics survey in which information regarding patients' age, profession, likability of music, likability of music during stressful or anxiety-producing situations (if applicable), preferred musical genre and previous musical education was collected. Subjects were informed they would start listening to the music pre-operatively while in the preoperative care unit (POCU) for approximately 20 minutes before being taken into the operating room and that the music would continue to play intra-operatively and post-surgery as well.

\section{Music Selection}

Enrolled subjects were randomized into two categories: Group I Music (subjects received music pieces composed in major keys) and Group II Music (subjects received compositions in minor keys). Patients were blinded to the Group I Music and Group II Music group distinction. Randomization was carried out on a rotary method (patients were alternately assigned to one of the two divisions). All musical compositions were instrumental and nonlyrical in nature (Table 1). All pieces were individually reviewed to ensure they met the 'sympathetic resonance' criteria. Subjects were blinded to the type of music they received.

\section{Pre-Operative Technique}

Approximately 30 minutes before the scheduled surgery time, subjects completed the Beck Anxiety Inventory (BAI), a 21-question multiple choice self-report inventory measuring subjects' severity of anxiety between 0 (this symptom doesn't bother at all) to 3 (this symptom severely bothers) (Table 2). Upon completion of the BAI, subjects were fitted with the noise-cancelling headphones. Volume of the music and positioning of earpieces to ensure comfort were adjusted to each individual's preference. Subjects were reminded that at any point the music could be turned off and the volume altered upon their request. Subjects were then taken into the operating room and prepped by the nursing staff and anesthesiologist. To ensure proper positioning of the headphones during surgery and prevent earbuds from falling out, the equipment was secured to the ear and scalp with Tega-Derm ${ }^{\circledR}$.

\section{Peri-operative Technique}

Anaesthesia was provided using local infiltration with $2 \%$ lidocaine for the insertion of the pins for rigid head fixation and $0.25 \%$ bupivacaine with epinephrine for the surgical incision. This was supplemented with sedation consisting of combination of shortacting drugs, such as midazolam, propofol, fentanyl, remifentanil or dexmedetomidine, depending on the anaesthesiologist's preference. All sedation was discontinued before brain mapping to ensure full patient cooperation in stimulation testing. Routine monitoring used on all patients included non-invasive blood pressure, pulse oximetry, and an electrocardiogram. End-tidal $\mathrm{CO}_{2}$ was monitored and supplemental oxygen was administered via nasal prongs or face mask. None of the patients had Foley catheters or arterial lines and mannitol was not used in any of the patients. The awake craniotomy technique is described in previous publications from our group. ${ }^{32,34}$

During surgery, patients were periodically asked about their comfort regarding the music and the volume level. Adjustments based on patient preference were made. Music was stopped during the intra-operative brain mapping portion of surgeries to prevent interference with dialogue with the surgeon. Once mapping was completed, the music was immediately resumed.

\section{Post-Operative Technique}

Following surgery, the Tega-Derm ${ }^{\circledR}$ surrounding the earbuds was removed and the scalp was covered with dressing. The music continued to play for approximately 20 minutes following surgery while subjects waited in the post-anesthesia care unit (PACU). After this time had elapsed, the music was turned off and the headphones were removed.

\section{Follow-Up}

During the subjects' follow-up appointment approximately two weeks after surgery, another BAI was administered. The BAI asked subjects to rate the 21 multiple choice questions regarding how they were feeling post-surgery and throughout their recovery process since their procedure (Table 2). Subjects were also administered a 12-item open-ended interview which assessed their thoughts and feelings regarding the music pieces which were played (Table 3).

\section{Data Collection}

All interviews, questionnaires and inventories were conducted in an open-ended, face-to-face style. All subjects were interviewed by a single interviewer, with no clinical relationship to the subject. A semi-structured guide containing questions pertinent to patients' perceptions regarding the music therapy was used (Table 3). Themes were freely explored as they emerged. All interviews were digitally audio-recorded and transcribed. Demographic parameters including age, marital status, education, and occupation were collected, as well as clinical data such as specific diagnosis and date(s) of surgery.

\section{Data Analysis}

Interviews were examined using modified thematic analysis involving open and axial coding. Open coding involves breaking down information into common groupings based on shared ideas, whereas axial coding involves organizing information according to overarching themes. ${ }^{6}$

\section{Research Ethics}

Participation was entirely voluntary, and informed consent was obtained from all participants. Both the confidentiality of patients and their freedom to withdraw from the study at any time with no consequence was explained and maintained. The study was approved by the Research Ethics Board of the University Health Network.

\section{RESULTS}

Demographic information from the 29 interviewed patients is included in Table 4. Of the 29 patients, two had focal seizures while on the table and one patient had a brief airway 
Table 1: Music selections in both Group 1 and Group 2

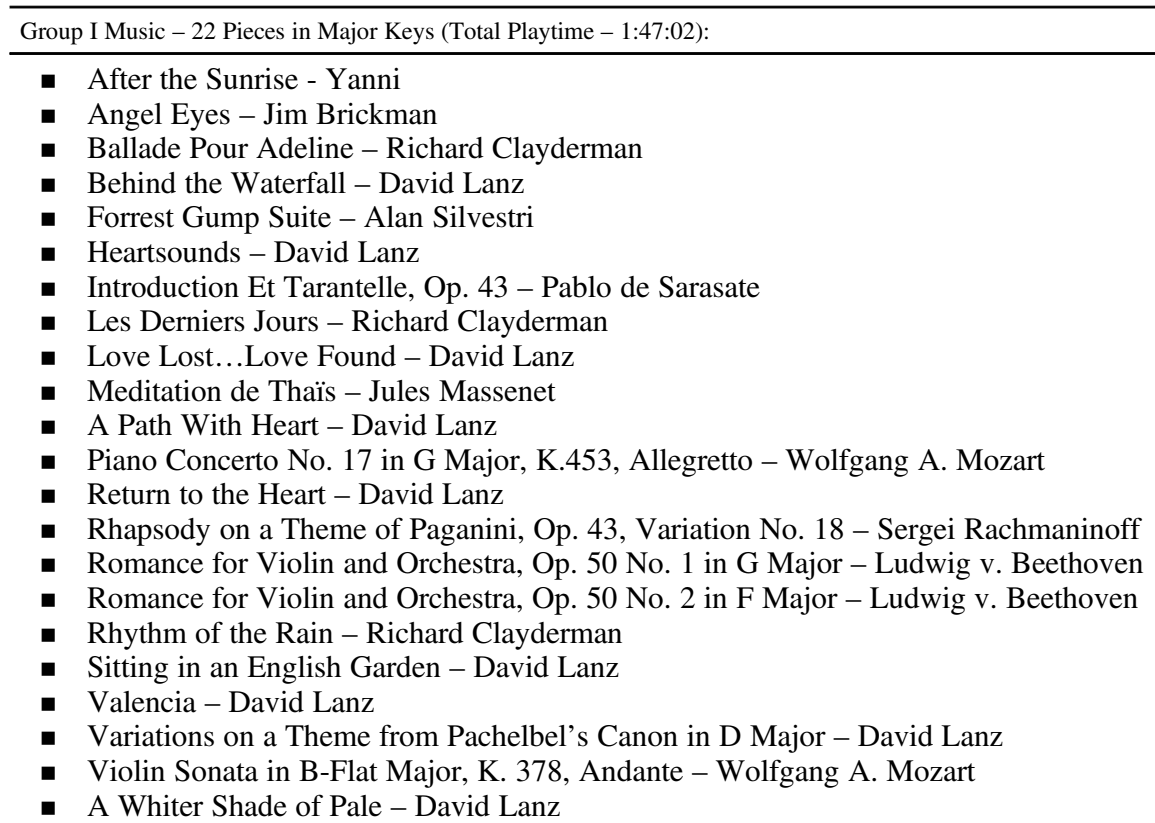

Group II Music - 22 Pieces in Minor Keys (Total Playtime - 1:49:07):

- Autumn Leaves - Richard Clayderman

- Besame Mucho - Richard Clayderman

- Brandenburg Concerto No. 1 in F, BWV 1046 - 2. Adagio - J. S. Bach

- Partita No. 2 in D minor, Chaconne - J. S. Bach

- L'Enfant Et La Mer - Richard Clayderman

- Eleana - Richard Clayderman

- Enchantment - Yanni

- Fantasy on Russian Themes - Fitz Kreisler

- Feelings - Richard Clayderman

- Greensleeves (Harp) - Sally Fletcher

- Légende Op. 17 in G minor - Henryk Wieniawski

- Mariage D'Amour - Richard Clayderman

- Nightingale - Yanni

- Nocturne Op. 48 No. 1 in C minor, Lento - Frédéric Chopin

- Nocturne Op. 55 No. 1 in F minor, Andante - Frédéric Chopin

- Nostalgia - Yanni

- One Man's Dream - Yanni

- Palladio - Karl Jenkins

- Passion - Richard Clayderman

- The Sound of Silence - Richard Clayderman

- Violin Concerto \#1 in A minor, BWV 1041 - 1. Allegro - J. S. Bach

- Zigeunerweisen, Op. 20 - Pablo de Sarasate

All pieces were analyzed to ensure they met the 'sympathetic resonance' criteria. Subjects were blinded to the type of music they received.

obstruction (Table 5). Adverse effects weren't associated with the musical intervention. Their responses were analyzed and the resulting data were organized into several themes, presented below.

\section{Regarding music at all three points, before, during and after the surgery, some patients preferred not to listen to the music before the surgery}

Some patients said they did the most amount of thinking about their surgery when they were waiting before the surgery and that this was associated with thoughts and feelings of anxiety, stress and fear. Having the music at this stage was good for some because it prevented them from hearing nearby conversations and over-thinking relatively negative thoughts. Other patients expressed that listening to music before the surgery was sometimes annoying or frustrating as they wanted to speak to their family members and doctors.

\section{Patients liked having music to listen to during the surgery}

Patients reflected that the aspects that they feared the most were hearing conversations they didn't want to hear during the 
Table 2: Beck Anxiety Inventory (BAI) given to patients in both pre-operative and post-operative cases to determine overall anxiety levels

\section{Beck Anxiety Inventory - Pre-Op}

Below is a list of common symptoms of anxiety. Please carefully read each item in the list. Indicate how much you have been bothered by that symptom during the past month, including today, by circling the number in the corresponding space in the column next to each symptom.

\begin{tabular}{|c|c|c|c|c|}
\hline & Not At all & Mildly - but it didn't bother me much & Moderately - it wasn't pleasant at times & Severely - it bothered me a lot \\
\hline Numbness or tingling & 0 & 1 & 2 & 3 \\
\hline Feeling hot & 0 & 1 & 2 & 3 \\
\hline Wobbliness in legs & 0 & 1 & 2 & 3 \\
\hline Unable to relax & 0 & 1 & 2 & 3 \\
\hline Fear of worst happening & 0 & 1 & 2 & 3 \\
\hline Dizzy or lightheaded & 0 & 1 & 2 & 3 \\
\hline Heart pounding/racing & 0 & 1 & 2 & 3 \\
\hline Unsteady & 0 & 1 & 2 & 3 \\
\hline Terrified or afraid & 0 & 1 & 2 & 3 \\
\hline Nervous & 0 & 1 & 2 & 3 \\
\hline Feeling of choking & 0 & 1 & 2 & 3 \\
\hline Hands trembling & 0 & 1 & 2 & 3 \\
\hline Shaky / unsteady & 0 & 1 & 2 & 3 \\
\hline Fear of losing control & 0 & 1 & 2 & 3 \\
\hline Difficulty in breathing & 0 & 1 & 2 & 3 \\
\hline Fear of dying & 0 & 1 & 2 & 3 \\
\hline Scared & 0 & 1 & 2 & 3 \\
\hline Indigestion & 0 & 1 & 2 & 3 \\
\hline Faint/lightheaded & 0 & 1 & 2 & 3 \\
\hline Face flushed & 0 & 1 & 2 & 3 \\
\hline Hot/cold sweats & 0 & 1 & 2 & 3 \\
\hline
\end{tabular}

procedure and feeling pain. These aspects, they felt, would make them become anxious and nervous. Having the music during the procedure prevented them from understanding conversations while on the surgical table which helped the patients calm down. Most patients commented that having the music was most important to them during the surgery itself. The only time patients said they would not have wanted to listen to music during the surgery was when they started to feel impatient; in these situations the music didn't allow them to feel any more relaxed.

\section{After surgery, some patients did not want to listen to the music anymore}

After the surgery and appropriate dressing had been finished, patients were taken to the PACU where they continued listening to the music. Often patients requested to have the volume of the music turned down or that it be shut off completely, partly because of post-surgical headaches or because the music was not comforting. For these patients the music was not helping them feel any more relaxed and it was causing them frustration. They felt pain and wanted peace and quiet which the music wasn't helping them attain. These subjects stated they would assume that they would have wanted to continue listening to the music if it weren't for the headaches. Patients who did not seem to have major headaches during the recovery period said that the music was helpful in calming them down and allowing them to relax.

Music helped patients by acting as a distraction to the actual surgical procedure and by helping them settle down and feel less anxious

Patients were awake and conscious for at least parts of their surgery, if not for all of it. When given the music, patients reported that it helped them because there was something other than their thoughts and feelings to focus on. Two patients even remarked that they felt nauseated while on the table and that the music helped distract them from the nausea. Patients said the music acted as something else to focus their attention towards.

Most patients also said that listening to the music brought down the anxiety and stress they were feeling. Many said they were feeling jittery and nervous and that, upon listening to the music, they felt less of these feelings. This decrease in anxiety, nervousness, and jitteriness wasn't felt immediately upon listening to the music by all patients; many said that it was listening to the music for a prolonged duration that that they believed helped them. In essence, the calming effects of the music were progressive and not necessarily immediate. 
Table 3: Study Interview

\section{PREAMBLE:}

The Effect of Music on Awake Craniotomy Patients Questionnaire (Interview Guide)

This interview is intended to explore your perceptions about the music that was provided to you before, during, and after your awake craniotomy and/or to discuss the overall experience you had with your surgery. Your input is important to us and will help us do a better job.

\section{INTERVIEW PROPER:}

1. How were you feeling a week prior to your scheduled awake craniotomy? During this time, did you experience any feelings of fear, stress, anxiety, or tension? If so, did those feelings interfere with your normal daily activities? Tell me more about it.

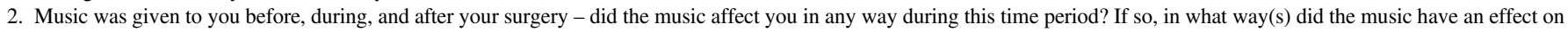
you? For instance, did you feel more at ease, or perhaps, feel a particular emotion while listening to the music? Tell me more about your experience.

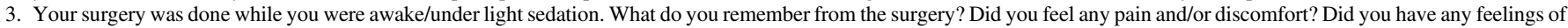
fear, stress, anxiety, or tension during the surgery? Tell me more about it.

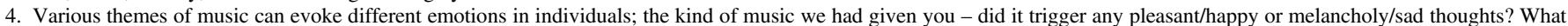
mood did you think the music expressed? Tell me more.

5. Do you recall hearing the types of instruments that were being played during the selections? If so, which instrument(s) were you able to hear/pick out?

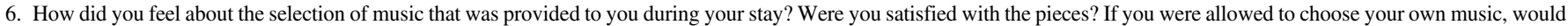
you have chosen something different from what we had given you?

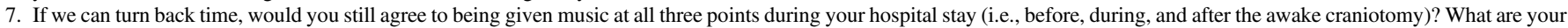
thoughts on this? Tell me more.

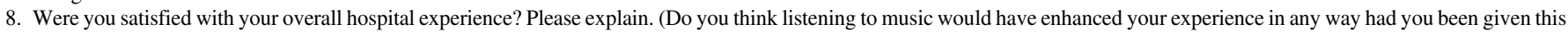
opportunity?) Tell me more about it.

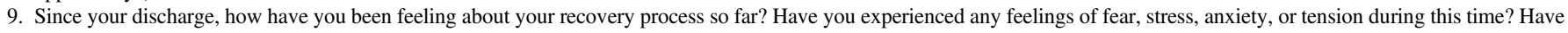
you been able to resume to your normal daily activities? Tell me more.

10. Do you have any suggestions as to how we can improve the whole surgical experience for the patient?

11. Is there anything else you would like to add?

These were the questions that patients were asked post surgery. Answers to these questions were used to provide thematic analysis through open and axial coding.

\section{For most patients the music did not trigger thoughts or emotions but helped them relax}

During the interview, patients were asked what type of thoughts or feelings were evoked when listening to the music. Nearly all of the patients were unable to respond to this question without being prompted. The interviewer then gave choices of whether the music evoked happy and cheerful thoughts or sad and melancholy thoughts. When given these options, the majority of subjects responded that thoughts were definitely not sad, melancholy or negative. However, they did not say that thoughts were necessarily positive nor happy either. Most patients reflected that their thoughts were neutral. Some patients explained that instead of thoughts, feelings, or moods evoked by the music, often the music brought back memories from their past. One individual reflected that his days of learning the piano were brought back to him and when asked how this made him feel, he replied that it was positive. Another subject said that she relived memories of a music appreciation course she took in university which she greatly enjoyed.

\section{The majority of patients were able to hear a violin in the music. For those who were unable to say which instrument they heard the most, they were able to respond that they remembered hearing many string instruments}

Of all 29 patients interviewed, a few said that they didn't recall anything about the music or the types of instruments which were played in their songs at all. This was largely due to the fact that these patients were well-sedated and almost asleep. When woken up for brain mapping, it took these patients a little longer to respond to the surgeon's requests. There were also a few patients who remembered hearing the music before, during and after the surgery but couldn't recall specifically what type of instruments were played. When prompted to think about a category of instruments, almost all of these subjects said they heard string instruments playing. Others said they recalled orchestral instruments. Many subjects were able to pinpoint specific instruments they had heard - the instrument that was most frequently recalled by subjects was the violin, closely followed by the piano.

\section{Many would've liked to pick their own music if they were to undergo the procedure again while others felt the music chosen for them was acceptable}

Subjects were asked what they thought of the music and would they have chosen differently if allowed to. Nearly half of the subjects responded that they would like their own music. Patients said their own music would help them feel less nervous, partially because of the familiarity of the music; since they would be choosing music they like and frequently listen to, they would be more in-touch with the surroundings and therefore feel more at ease and calm. One individual commented that the music he received, although he was grateful for it, was "boring" and that having his own music would have given him something else to focus on during the surgery. Subjects who expressed that they would not want to select their own music said it was because they were afraid that later, after the surgery, they would associate those songs with the surgery and that this would not be very pleasant for them. Some also said that they would not have chosen music which had the same calming and relaxing effect as the music they were given and that this would not have helped them during their procedures.

In selecting two pieces that were preferred out of four, subjects either chose both of the major key or minor key pieces, not a combination of both

During the interview patients listened to a one minute duration of four pieces, first, Rhythm of the Rain by Richard Clayderman, second, Adagio in G Minor by Tomaso Albinoni, third, Barber of 
Table 4: Demographic data of 29 interviewed patients

\begin{tabular}{|c|c|}
\hline Characteristics & Value \\
\hline \multicolumn{2}{|l|}{ Age (years) } \\
\hline Range & $22-78$ \\
\hline Mean & 52 \\
\hline \multicolumn{2}{|l|}{ Sex } \\
\hline Male & 15 \\
\hline Female & 14 \\
\hline \multicolumn{2}{|l|}{ Education } \\
\hline Less than high school & 8 \\
\hline High school or equivalent & 5 \\
\hline College diploma & 3 \\
\hline Bachelor's degree & 5 \\
\hline Master's degree & 5 \\
\hline Doctoral degree & 1 \\
\hline Other & 2 \\
\hline \multicolumn{2}{|l|}{ Occupation } \\
\hline Engineering & 1 \\
\hline Information Technology Consultant & 2 \\
\hline Service industry & 8 \\
\hline Administration & 1 \\
\hline Educator & 1 \\
\hline Retired & 2 \\
\hline None & 12 \\
\hline Other & 2 \\
\hline \multicolumn{2}{|l|}{ Marital status } \\
\hline Single & 7 \\
\hline Married & 17 \\
\hline Divorced & 4 \\
\hline Widowed & 1 \\
\hline
\end{tabular}

Seville Overture by Giochino Rossini and lastly, Bradenburg Concerto No. 1 in F Major, BWV 1046 Adagio by J.S. Bach. The first and third pieces were major key pieces and the second and fourth were minor key pieces. When asked to select two pieces they felt would help them better alleviate their fear/stress/anxiety/nervousness and which they would prefer listening to during the surgery, all subjects either chose the major key or minor key pieces. None of the subjects chose one major key and one minor key piece.

\section{The subjects who preferred the major key pieces did so because of the feelings the music evoked}

Of the subjects who chose the major key pieces, it was because these sounded more happy and up-beat. They evoked light and cheerful moods and feelings in most of the patients and these were the type of emotions that they wanted to have evoked during their surgical procedure. In thinking about the other two pieces, subjects said that these were discounted because they seemed sad, melancholy and like funeral marches to them. A few patients concluded that they would take the positive, happy feelings, emotions and moods over the sad and dark ones.
Table 5: Anaesthetic drugs given to 29 study patients with commentary on complications

\begin{tabular}{|c|c|c|}
\hline & Anesthesia & Complications \\
\hline 1. & $\mathrm{M}+\mathrm{P}+\mathrm{O}$ & \\
\hline 2. & $\mathrm{M}+\mathrm{P}+\mathrm{O}$ & \\
\hline 3. & $\mathrm{M}+\mathrm{P}+\mathrm{O}$ & \\
\hline 4. & Dexmed & \\
\hline 5. & Dexmed & \\
\hline 6. & Dexmed & \\
\hline 7. & $\mathrm{M}+\mathrm{P}+\mathrm{O}$ & \\
\hline 8. & $\mathrm{M}+\mathrm{P}+\mathrm{O}$ & \\
\hline 9. & Dexmed & \\
\hline 10. & $\mathrm{M}+\mathrm{P}+\mathrm{O}$ & \\
\hline 11. & $\mathrm{M}+\mathrm{P}+\mathrm{O}$ & \\
\hline 12. & Dexmed & \\
\hline 13. & $\mathrm{M}+\mathrm{P}+\mathrm{O}$ & Seizures \\
\hline 14. & Dexmed & \\
\hline 15. & Dexmed & \\
\hline 16. & Dexmed & \\
\hline 17. & $\mathrm{M}+\mathrm{P}+\mathrm{O}$ & \\
\hline 18. & $\mathrm{M}+\mathrm{P}+\mathrm{O}$ & \\
\hline 19. & Dexmed & Over sedation/brief airway obstruction \\
\hline 20. & Dexmed & \\
\hline 21. & Dexmed & \\
\hline 22. & $\mathrm{M}+\mathrm{P}+\mathrm{O}$ & \\
\hline 23. & $\mathrm{M}+\mathrm{P}+\mathrm{O}$ & Seizures \\
\hline 24. & $\mathrm{M}+\mathrm{P}+\mathrm{O}$ & \\
\hline 25. & $\mathrm{M}+\mathrm{P}+\mathrm{O}$ & \\
\hline 26. & Dexmed & \\
\hline 27. & Dexmed & \\
\hline 28. & Dexmed & \\
\hline 29. & Dexmed & \\
\hline
\end{tabular}

Dexmed $=$ dexmedetomidine (new drug); $\mathrm{M}+\mathrm{P}+\mathrm{O}=$ midazolam, propofol, opioid (conventional)

The subjects who preferred minor key pieces did so because of the rhythm and tempo of the music

Just a little less than half of the subjects preferred the two minor key music pieces better than the major key ones when selecting for those best to help alleviate unwanted anxiety. Patients said they preferred these pieces because they were slower and steadier and less up-beat and fast-paced. This helped them relax and settle into a calmer mood. They commented that the faster tempo pieces were not ideal in helping them calm down.

\section{Subjects gave different opinions of minor key music during the surgery compared to responses to those pieces played} during the interview

During the interview, patients who had listened to minor key music during their surgery said that the music wasn't sad or 
melancholy nor did it evoke any thoughts or feelings along these lines. These subjects also did not state that the music was happy either. In fact, most were neutral regarding their thoughts on the tone of music that they had heard. However, of these subjects, those who had chosen the major key pieces (excerpts from songs two and four of the four pieces played to them) were able to accurately say that the minor key pieces were sad and solemn. The subjects who preferred the minor key pieces, may have subliminally thought this as well but reflected that they chose these pieces largely due to speed and not mood. This relationship was not found in patients who had listened to major key music during the day of surgery.

\section{Overall, patients liked having the music to listen to}

While there were patients who did not want the music in the pre-operative and post-operative stages and also those who said they would have enjoyed the music more if it had been of their own selection, the large majority of subjects were glad they had music to listen to. None of the patients stated any negative or adverse reaction to the music nor stated that they did not enjoy the music. There was no significant difference between the two groups in regards to whether they liked the music or not overall.

The patients who remembered listening to music before, during and after their awake cranial surgery reported that the music had a positive effect on their whole experience. This was attributed to the fact that having the music made the surgery much less stressful and anxiety-producing. Patients said they were able to look upon their whole experience in a much more positive light because of the fact that the surgery went so well and they felt much more relaxed and at ease than they had anticipated. When pondering why they felt so positive, nearly every patient attributed this to two factors: simply having music to listen to and because they had so much confidence in the surgical team. Only two patients reflected that the music didn't really impact their experience in either a positive or negative manner. They felt that it was more about knowing what was to come, the comfort given to them by the nurses, and the confidence they held in the surgical team which was more important to them than the music. None of the subjects reflected that the music had impacted them, even slightly, in a negative manner.

\section{Many patients suggested that music should always be an option for every awake surgery, not just for study purposes}

One of the last questions that patients were asked as a part of their interview was what type of suggestions they would make to improve the whole surgical experience. Most patients said they were satisfied with how their surgery had played out and had no other suggestions. However, over one third of the patients suggested that music should be implemented in every awake surgery since they thought it had helped them so much. These individuals explained that all patients should have the opportunity to listen to music if they want, whether their own or selected for them. They felt the important thing was that there be something to listen to in an otherwise stressful procedure.

\section{DISCUSSION}

Awake cranial surgery can be stressful and anxiety-producing for some patients. Even patients who have had previous brain surgeries, whether in awake or general anesthetic conditions, are likely to be just as nervous for future procedures. ${ }^{19}$ Keeping the patient calm, steady, and relaxed during these procedures is important for patients and surgeons alike. When patients on the table begin moving or are unable to keep calm, the surgical team must wait till the patient has stabilized; the surgery takes longer than anticipated. Furthermore, studies have shown that adverse effects related to anxiety and stress negatively impact patient recovery in both a physical and psychological manner. ${ }^{3}$ Therefore, it is in everyone's best interest to ensure that patients are as relaxed and stress-free as possible, especially before and during the surgery. While many studies have investigated different means by which to keep patients in optimal condition, few studies have looked at the impact of music before, during, and after surgery. To our knowledge, no studies have investigated this relationship at all three time points during an awake craniotomy procedure. The present qualitative study allowed us to examine the effects of music and tonality on patients undergoing awake cranial surgery.

Overall, patients strongly expressed preference towards being given music to listen to, starting pre-operatively, continuing throughout the surgery and ending after being in the PACU for nearly 30 minutes. The music was described as being calming, soothing, and relaxing. Patients said it distracted them from thinking negatively or feeling anxious and jittery. Music has been reported previously in clinical settings to have profound physiological effects in the pre-operative stage. Previous studies have found significant decreases in heart rate, systolic blood pressure, diastolic blood pressure, mean arterial blood pressure, respiratory rate, myocardial oxygen demand, use of morphine sulfate, psychological distress, and anxiety, and happier emotional state or mood when patients are given music to listen to in a variety of surgical procedures. ${ }^{31}$ In correlating such psychological and physiological quantitative data with the qualitative responses received in the present study, it can be stated that some types of music indeed have a relaxing, anxiety decreasing and calming effect on patients undergoing awake surgery. Patients explained that they believed the music helped them because it offered an outlet for them. Should they not have received the music, the only option was to lie on the table listening to the conversations surrounding them or thinking about what was happening. Having the music to listen to, despite the fact that most patients never listened to classical, non-lyrical music for leisure, gave subjects a distraction and something to think about.

Some patients expressed not wanting to listen to the music in the pre-operative and/or post-operative stage. There were a variety of reasons why this was the case. Many studies have stated that the pre-operative period is the time of greatest stress and anxiety experienced by the patient. ${ }^{13,29,37}$ The music distracted patients from speaking with their doctors and family members. Patients felt it was really important to speak to family at this time point since they were unsure of the outcomes in such a major surgery and wanted to spend the most time possible together while they had a chance. After surgery, the music was sometimes annoying and frustrating to patients who experienced headaches. At other times, patients reflected that they just wanted peace and quiet and the music interfered with this. While the music was helpful during the surgery, before and after, some of the patients had other priorities with which, they believed, the music interfered.

It seemed slightly surprising that subjects weren't able to attribute the kinds of thoughts or emotions the music evoked. 
Even when prompted with leading questions, subjects were not quick to agree or disagree to a prompt. It was clear that the majority of the subjects enjoyed the music even if not during all time points. However, when asked if this was due to any positive feelings, moods, or emotions they were unable to respond. It is not clear why this is the case, however, one speculation is that patients intentionally tried not to think about how they felt about the music. Waiting to go into a potentially life changing surgery, lying awake on an operating table or having emerged from a major surgery are all situations in which it is safe to say one is flooded with thoughts, emotions, and moods. Perhaps the music was a way by which these overwhelming sensations were stopped. In essence, it could be that patients were simply listening to the music without consciously thinking or feeling as a way to stop feeling overwhelmed. If this is true, it may provide insight as to why patients were so satisfied with the music. Alternatively, while specific moods and thoughts evoked by the music could not be recounted, some patients did reflect that the music stirred up pleasant memories. Thus it can be hypothesized that, in these cases, the memories brought forth by the music evoked certain moods and thoughts and patients may have linked them to the memories and not the music.

Another interesting aspect to consider is that patients chose either the major key or the minor key compositions to listen to when asked (in Question 6 of the post-operative interview) to pick two selections of the given four (Table 4). Although there were patients who liked one or both of the other pieces that they did not select, none of the subjects felt as strongly about those in comparison to the two they had selected. The majority of patients (just over half) preferred both of the major key pieces while the remainder indicated they would choose the minor key pieces. Major keys are generally perceived as happy and joyful (especially in Western cultures) while minor keys are noted to be sad and glum. ${ }^{5}$ Minor key music is speculated to be perceived this way because of cultural conditioning. ${ }^{8}$ When asked to express sadness in their voices, psychological studies show that the majority of peoples' sound melodies and intonation follow a minor third interval. These results are also shown by speakers of other non-Western languages and even from tribes who have not been exposed to Western culture at all. $^{4}$ This, and other examples, indicate that the human brain is hardwired to associate minor keys with negative and sad themes. If this is true, then it is counterintuitive that just less than half of the subjects in this study actually preferred wanting to listen to minor key music over the pieces composed in major key.

Psychological studies in the past decade have found that, in general, people tend to prefer minor key music. ${ }^{8}$ While this is peculiar, aspects other than tonality should be taken into consideration. When other aspects of music like tempo are factored in, the reasons for this counterintuitive occurrence start to seem more logical. In Question 6 (Table 4), we found that subjects preferred major key music on the basis of tonality and minor key music when evaluating based on suitable tempo. Therefore a likely explanation may be that while the minor key pieces may indeed have sounded more melancholy, subjects were choosing based on other criteria, like speed, and may have discounted tone when selecting. The patients who selected minor key music mostly reasoned their choice based on liking the slow movement and speed of the songs when compared to the faster and up-beat major key songs. Alternatively, it could also be that since the music was non-lyrical in nature and unfamiliar in genre compared to what most patients normally listened to, it would have been more difficult for the untrained ear to hear differences in tone. This is supported by the fact that patients gave different opinions of the music when listening on surgery day in comparison to listening during the interview. When patients who had listened to minor key music were asked what kind of thoughts and emotions the music reflected, the majority said that they were definitely not sad but were unable to pinpoint if they were happy or neutral. However, when two of the same pieces were played to them again and they were prompted to chose two of the four and be ready to explain why and how they had come about their selection, patients became more aware of tone of composition. Therefore, it may very well be the case that patients use many cues when choosing music they prefer and not just those most obvious.

The two most common suggestions that patients made were: (1) give everyone a choice to have music to listen to during surgery; and (2) let patients pick their own music. While the vast majority of patients did not have any suggestions to make, people were satisfied in general to receive the music therapy. Only if patients were content with having a musical intervention would they suggest that it should be mandatory to ask patients if they wanted to listen to music during their procedure. One patient said she had already asked nurses if she was allowed to have noise dampening earplugs inserted for the duration of the surgery to escape having to listen to conversation between the staff during surgery, which has indeed been shown to be unsettling to patients. ${ }^{39}$ In suggesting that patients be able to choose their own music, it can be interpreted that patients reacted positively to receiving the music and that they thought that should they have been able to choose music of their own preference, they would be more than satisfied.

\section{Conclusion}

This study aimed to determine the effects music and, more specifically, its tonality in regards to major and minor key divisions during the pre-operative, peri-operative, and post-operative periods of an awake craniotomy. Modified thematic analysis of patients' responses during a post-operative open-ended interview showed that, overall, patients were satisfied with the musical therapy they received and thought that it should be continued for all patients if the subjects wished so. The music helped patients feel relaxed and at ease and this was largely because it provided a distraction from the sounds and feelings they were experiencing while on the surgical table. Patients, overall, were satisfied with the non-lyrical major and minor key instrumental pieces they listened to. Patients did not seem to significantly prefer one key over the other when asked in their interview what they would prefer to listen to in order to alleviate stress, anxiety and fear.

Since one of the major themes emerging from this analysis was that patients liked to have music intervention because it provided a distraction from their personal thoughts and the sounds of the operating room, other aspects of audio distraction may also have potential. In the future, having patients listen to a short narrative, excerpt or chapter from a longer story should be investigated. When listening to narratives, subjects would have to follow the plot events, characters' names and personalities, setting and other aspects to be able to follow along with the story. This may be beneficial as it could prove better at preventing subjects from thinking about unpleasant 
or anxiety-producing ideas than background music would. In essence, the better the distraction, the better the satisfaction that patients would feel towards their surgical procedures.

\section{Disclosures}

None to disclose. The authors report no conflicts of interests, and are alone responsible for the content and writing of the article.

\section{REFERENCES}

1. Badner NH, Nielson WR, Munk S, Kwiatkowska C, Gelb AW. Preoperative anxiety: Detection and contributing factors. Can J Anaesth. 1990;37:444-7.

2. Bailey L. Strategies for decreasing patient anxiety in the perioperative setting. AORN J. 2010;92:445-60.

3. Beez T, Boge K, Wager M, et al. Tolerance of awake surgery for glioma: A prospective European low grade glioma network multicenter study. Acta Neurochir (Wien). 2013;155:1301-8.

4. Bowling DL. A vocal basis for the affective character of musical mode in melody. Front Psychol. 2013;4:464.

5. Collier WG, Hubbard TL. Musical scales and evaluations of happiness and awkwardness: Effects of pitch, direction, and scale mode. Am J Psychol. 2001;114:355-75.

6. Corbin J, Strauss A. Basics of Qualitative Research: Techniques and Procedures for Developing Grounded Theory. Thousand Oaks, Sage; 2008

7. Cunningham MF, Monson B, Bookbinder M. Introducing a music program in the perioperative area. AORN J. 1997;66:674-82.

8. Curtis ME, Bharucha JJ. The minor third communicates sadness in speech, mirroring its use in music. Emotion. 2010;10:335-48.

9. Cutshall S, Derscheid D, Miers AG, et al. Knowledge, attitudes, and use of complementary and alternative therapies among clinical nurse specialists in an academic medical center. Clin Nurse Spec. 2010;24:125-31.

10. Daniels GJ, McCabe P. Nursing diagnosis and natural therapies A symbiotic relationship. J Holist Nurs. 1994;12:184-92.

11. Davidson JW, Magee W. The effect of music therapy on mood states in neurological patients: A pilot study. J Music Ther. 2002;39: 20-29.

12. Davis T, Jones P. Music therapy. Decreasing anxiety in the ventilated patient: A review of the literature. Dimens Crit Care Nurs. 2012;31:159-66.

13. Devinsky O, Barr WB, Vickrey BG, et al. Changes in depression and anxiety after resective surgery for epilepsy. Neurology. 2005;65: 1744-9.

14. Evans D. The effectiveness of music as an intervention for hospital patients: A systematic review. J Adv Nurs. 2002;37:8-18.

15. Fredriksson A, Hellström L, Nilsson U. Patients' perception of music versus ordinary sound in a postanaesthesia care unit: A randomised crossover trial. Intensive Crit Care Nurs. 2009;25:208-13.

16. Gillen E, Biley F, Allen D. Effects of music listening on adult patients' pre-procedural state anxiety in hospital. Int J Evid Based Healthc. 2008;6:24-49.

17. Hevner K. The affective character of the major and minor modes in music. Am J Psychol. 1935;47:103-18.

18. Jääskeläinen J, Randell T. Awake craniotomy in glioma surgery. in Westphal M, Tonn JC, Ram Z (editors) Local Therapies for Glioma: Present Status and Future Developments. New York, Springer, 2003, pp 31-5.
19. Johnson JE, Leventhal H, Dabbs JM Jr. Contribution of emotional and instrumental response processes in adaptation to surgery. J Pers Soc Psychol. 1971;20:55-64.

20. Kane EO. Phonograph in operating-room. J Am Med Assoc. 1914; 62:1829.

21. Kellaris JJ, Kent RJ. An exploratory investigation of responses elicited by music varying in tempo, tonality, and texture. J Consum Psychol, 2:381-401, 1993.

22. Khu KJ, Doglietto F, Radovanovic I, et al. Patients' perceptions of awake and outpatient craniotomy for brain tumor: A qualitative study: Clinical article. J Neurosurg. 2010;112: 1056-60.

23. Lazaroff I, Shimshoni R. Effects of medical resonance therapy music on patients with psoriasis and neurodermatitis-a pilot study. Integr Physiol Behav Sci. 2000;35:189-98.

24. Leardi S, Pietroletti R, Angeloni G, et al. Randomized clinical trial examining the effect of music therapy in stress response to day surgery. Br J Surg. 2007;94:943-7.

25. McCaffrey R. Music listening: Its effects in creating a healing environment. J Psychosoc Nurs Ment Health Serv. 2008;46: $39-44$.

26. Nilsson U. The anxiety-and pain-reducing effects of music interventions: A systematic review. AORN J. 2008;87:780-807.

27. Norred CL. Minimizing preoperative anxiety with alternative caringhealing therapies. AORN J. 2000;72:838-43.

28. Pittman S, Kridli S. Music intervention and preoperative anxiety: An integrative review. Int Nurs Rev. 2011;58:157-63.

29. Reuber M, Andersen B, Elger CE, Helmstaedter C. Depression and anxiety before and after temporal lobe epilepsy surgery. Seizure. 2004; $13: 129-35$

30. Rigg MG. The mood effects of music: A comparison of data from four investigators. J Psychol. 1964;58:427-38.

31. Sendelbach SE, Halm MA, Doran KA, Miller EH, Gaillard P. Effects of music therapy on physiological and psychological outcomes for patients undergoing cardiac surgery. J Cardiovasc Nurs. 2006;21:194-200.

32. Serletis DF, Bernstein M. Prospective study of awake craniotomy used routinely and nonselectively for supratentorial tumors. J Neurosurg. 2007 Jul; 107(1):1-6.

33. Sidorenko VN. Clinical application of medical resonance therapy music in high-risk pregnancies. Integr Physiol Behav Sci. 2000;35:199-207.

34. Taylor MD, Bernstein M. Awake craniotomy with brain mapping as the routine surgical approach to treating patients with supratentorial intraaxial tumors: A prospective trial of 200 cases. J Neurosurg. 1999;90:35-41.

35. Wang S, Kulkarni L, Dolev J, Kain ZN. Music and preoperative anxiety: A randomized, controlled study. Anesth Analg. 2002; 94:1489-94.

36. Whittle I, Midgley S, Georges H, Pringle A, Taylor R. Patient perceptions of "awake" brain tumour surgery. Acta Neurochir. 2005; $147: 275-7$

37. Wrench J, Wilson SJ, Bladin PF. Mood disturbance before and after seizure surgery: A comparison of temporal and extratemporal resections. Epilepsia. 2004;45:534-43.

38. Yung PMB, Chui-Kam S, French P, Chan TMF. A controlled trial of music and pre-operative anxiety in chinese men undergoing transurethral resection of the prostate. J Adv Nurs. 2002;39: 352-9.

39. Zener RF, Bernstein M. Gender, patient comfort and the neurosurgical operating room. Can J Neurol Sci. 2011;38:65-71. 